\title{
Correction to: A New Correlation Equation for Calculating the Frictional Torque of the Nut at Different Feed Velocities and Nut Temperatures
}

\author{
Tzu-Chien Kuo ${ }^{1}$ - Yih-Chyun Hwang ${ }^{2}$ · Wen-Hsin Hsieh ${ }^{3}$
}

Published online: 1 February 2021

(c) Korean Society for Precision Engineering 2021

\section{Correction to: \\ International Journal of Precision Engineering and \\ Manufacturing (2021) 22:41-50 \\ https://doi.org/10.1007/s12541-020-00448-z}

During the correction process unfortunately the author photos in the biography section have been interchanged. The correction biographies should be as follows.

The original article has been corrected.

Publisher's Note Springer Nature remains neutral with regard to jurisdictional claims in published maps and institutional affiliations.

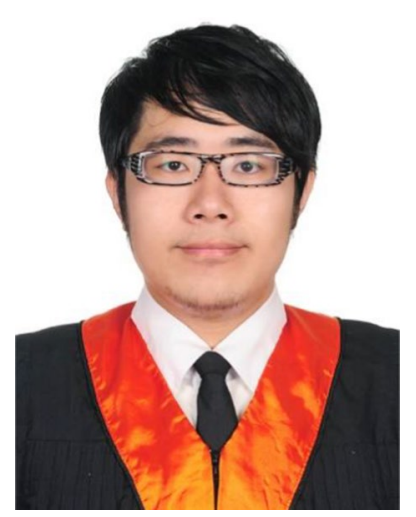

Tzu-Chien Kuo is a Ph.D. candidate in the Department of Mechanical Engineering, National Chung Cheng University, Taiwan. His main academic research interests are heat generation, heat transfer and thermal errors of machine tools.

The original article can be found online at https://doi.org/10.1007/ s12541-020-00448-z.

Wen-Hsin Hsieh

imewhh@ccu.edu.tw

1 Department of Mechanical Engineering, National Chung Cheng University, Chiayi 621, Taiwan, ROC

2 HIWIN Technologies Corp, Taichung 408, Taiwan, ROC

3 Department of Mechanical Engineering and Advanced Institute of Manufacturing With High-Tech Innovations, National Chung Cheng University, Chiayi 621, Taiwan, ROC

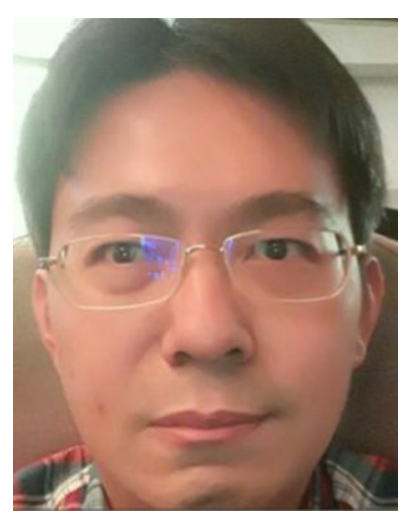

Yih-Chyun Hwang received his Ph.D. in mechanical and Electromechanical engineering from the National Sun Yat-Sen University, Taiwan in 2006. He is currently a general manager in R\&D Dep. in HIWIN, Taiwan. His research interests are in the fields of Tribology and linear components design.

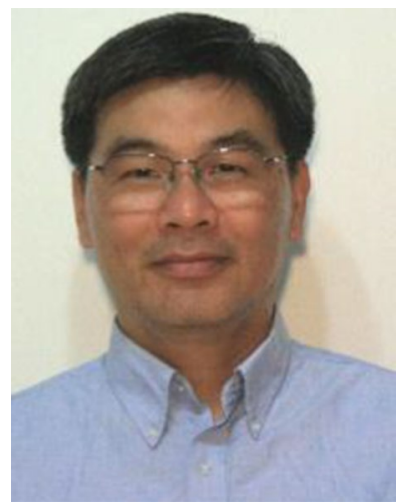

Wen-Hsin Hsieh received his Ph.D. in mechanical engineering from the Pennsylvania State University, University Park, PA, USA in 1987 . He is currently a distinguished professor with the Department of Mechanical Engineering at National Chung Cheng University, Taiwan. His research interests are in the fields of heat transfer, thermal analysis and thermal errors of machine tools, bio-chip, microfluidics and combustion. 